NASA Technical Memorandum 86779

NASA-TM-86779 19860022079

\title{
Simulation Evaluation of Display/Flir Concepts for Low Altitude Terrain-Following Helicopter Operations
}

Harry N. Swenson, Clyde H. Paulk, Jr., Robert L. Kilmer and Frank G. Kilmer

\section{FOR RERERENCE}

December 1985

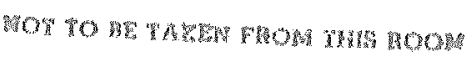

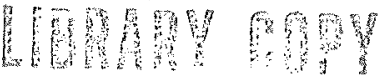 \\ FEBG 166}

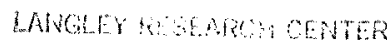

LBRARY, WAGA

HAMPTON, VIRCINUA

\section{N/Sก}

National Aeronautics and

Space Administration 
ERRATA

NASA Technical Memorandum 86779

SIMULATION EVALUATION OF DISPLAY/FLAIR CONCEPTS FOR LOW ALTITUDE TERRAIN-FOLLOWING HELICOPTER OPERATIONS

Harry N. Swenson, Clyde H. Paulk, Jr., Robert Kilmer and Frank G. Kilmer December 1985

There is an error in the title of this publication on the cover, the title

page and on the COSATI page. The title should read as follows:

SIMULATION EVALUATION OF DISPLAY/FLIR CONCEPTS FOR LOW ALTITUDE TERRAIN-FOLLOWING HELICOPTER OPERATIONS

Issued: August 28, 1986 


\section{Simulation Evaluation of Display/Flir Concepts for Low Altitude Terrain-Following Helicopter Operations}

Harry N. Swenson,

Clyde H. Paulk, Jr., Ames Research Center, Moffett Field, California Robert L. Kilmer,

Frank G. Kilmer, IBM, Federal Systems Division, Owego, New York

\section{NRSA}

National Aeronautics and

Space Administration

Ames Research Center

Moffett Field, California 94035 


\section{SIMULATION EVALUATION OF DISPLAY/FLIR CONCEPTS FOR LOW-ALTITUDE, TERRAIN-FOLLOWING HELICOPTER OPERATIONS}

Harry N. Swenson and Clyde H. Paulk, Jr. $\dagger$

NASA Ames Research Center, Moffett Field, California

Robert L. Kilmer $\neq$ and Frank G. Kilmer

IBM, Federal Systems Division, Owego, New York

\section{Abstract}

A piloted simulation of three head-down display (HDD) concepts with flight-director guidance superimposed on forward-looking infrared (FLIR) imagery was performed to evaluate the task of low-level, terrain-following (TF), manual helicopter flight. The three display concepts were exarined for the purpose of finding ways by which aircraft flight-attitude and cormand symbols and FLIR imagery could be integrated onto one instrument. In all cases, the FLIR imagery was centered on the flight-path vector of the aircraft. The three displays were then characterized by having 1) pitch attitude conformal to the FLIR imagery; 2) pitch attitude conformal to the FLIR imagery, but with an increase in the scaling; and 3) pitch attitude nonconformal to the FLIR imagery with the same pitch scaling as in (2). The simulation was conducted on the Vertical. Motion Simulator (VMS) at Ames Research Center, using NASA and Air Force test pilots. The pilots performed the TF task (over various types of terrain characteristics) by following flight-director symbols derived from terrain-following and course-steering guidance developed for the $\mathrm{HH}-60 \mathrm{D}$ helicopter. The pilots indicated that the nonconformal pitch attitude and FLIR display was the preferred way to display information because of the absence of pitchattitude information on displays (1) and (2) during some portions of the operational flight envelope and because of the difficulty in interpreting pitch attitude with displays (1) and (2) even when available.

\section{Introduction}

A requirement for low-level, nighttime, adverse-weather helicopter capability has been identified by the military. To meet this requirement, sensor data from terrain-following (TF) radar, forward-looking infrared (FLIR) imagery, and autonomous navigation instruments (e.g., iner$t$ lal navigation systems and Doppler radars) are being integrated through mission computers to produce guidance and display information for the pilot. One crucial question is how to integrate all the sensor information so the pilot can

"Aerospace Engineer. Member AIAA, AHS.

†Aerospace Engineer. Member AIAA.

\#Systems Eng ineer. Member AIAA.

\$Senior Engineer.

This paper is declared a work of the U.S. Government and therefore is in the public domain. accomplish the task with an acceptable level of compensation and work load.

A combination of the instruments mentioned above was used in a previous USAF helicopter program, H-53 Pave Low III. There were two primary pilot displays for that system. The first was a head-down display (HDD) with FLIR imagery, and with only TF command symbols superimposed. The second display, located above the FLIR, was an electromechanical attitude-director indicator (ADI) with an associated flight director. The pilot therefore had to switch between FLIR and the ADI to get all the aircraft attitude, command, and FLIR information that was required for flight. The U.S. Army's AH-64 advanced attack hellcopter is equipped with a pilot night-vision system (PNVS). This system provides aircraft status and FLIR imagery on a helmet-mounted display for use in nighttime, nap-of-the-Earth (NOE) manual flight; it does not provide flight-dlrector or any other type of command information. The USAF's HH-60 helicopter, now in development, will be equipped with a pilot display system that incorporates FLIR imagery, aircraft status, and command symbols onto one HDD.

Ames Research Center, together with IBM Federal Systems Division (prime contractor for the HH-6OD Avionics) and the USAF, initiated a simulation evaluation to examine low-altitude, terrainfollowing, manual flight operations of helicopters. The objective of this evaluation was 1) to investigate means of integrating aircraft attitude and command symbols with FLIR imagery onto one instrument and 2) to validate guidance laws for low-speed, TF manual flight. Using the Sikorsky UH-60A as a representative class of helicopter, three head-down display (HDD) concepts with superimposed FLIR imagery were evaluated for the pilot tasks of 1) constant-speed terrain-following and course-steering, and 2) terrain-following transition to approach and hover. These tasks were simulated over various terrain profiles, under day and night conditions, with and without winds and turbulence.

\section{Simulation Description}

\section{Vertical Motion Simulator}

Motion System. The evaluation was conducted at Anes research Center on the six-degree-offreedom Vertical Motion Simulator (VMS) shown in Fig. 1. The VMS provides extensive cockpit motion 


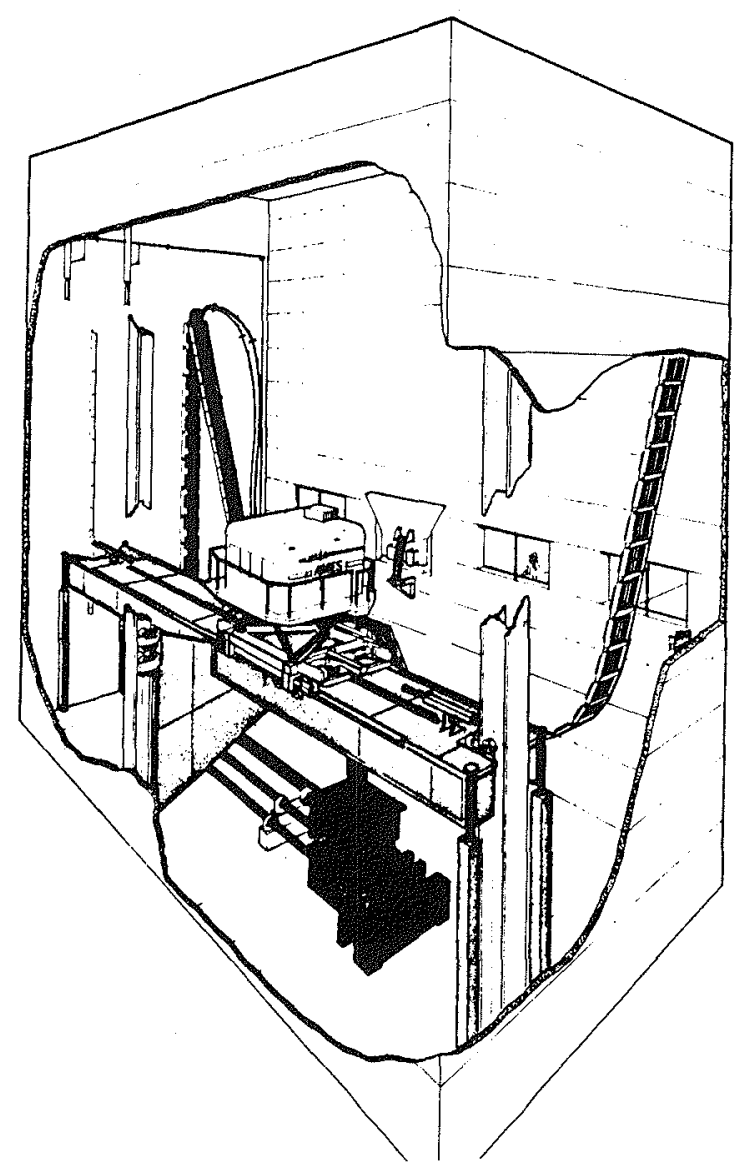

Fig. 1 Vertical Motion Simulator. for use in studying the handing qualities of and advanced guidance concepts for existing and proposed aircraft. ${ }^{2}$ The rotational and longitudinal motion are provided by a six-legged (hexapod) hydraulic motion system. This system is mounted on a moving platform with large vertical and lateral motion capabilities. The vertical degree of freedom provides the largest motion capability-$\pm 25 \mathrm{ft}$ displacement and $\pm 0.74 \mathrm{~g}$ 's. Lateral motion is provided by a carriage that is driven across the vertical drive platform; it provides $a \pm 17-\mathrm{ft}$ displacement and a $0.47-g$ capability.

Visual System. The visual system, a SingerLink digital image generator (DIG), nominaliy consists of a four-window display of computergenerated imagery (CGI). During the evaluation discussed in this paper there was a requirement for the FLIR instrument to be driven by a separate eye-point and pointing direction so as to simulate an FLIR field of view (FOV) centered on the flight-path vector of the helicopter. The capability developed during a previous simulation ${ }^{3}$ to allow multiple eye points for the visual scene was used for this purpose, but at the sacrifice of one of the four windows.

There were two distinctly different types of CGI data bases used for the simulation. The first one (Fig. 2) consisted of a detailed modeled area of about 4 square miles developed for nap-of-theEarth (NOE) simulations. ${ }^{3}$ The data base consisted of pyramid-shaped hilis with altitudes ranging from 0 to $1,000 \mathrm{ft}$; it also contained trees and buildings. This data base was primarily used for pilot training. The second data base comprised five mountain sets (Fig. 3). The sets consisted of a series of parallel, 3,000-ft-long, inverted$V$-shaped peaks. The number of peaks, the heights of the peaks, the widths of the bases, and the distances between peaks varied from set to set.

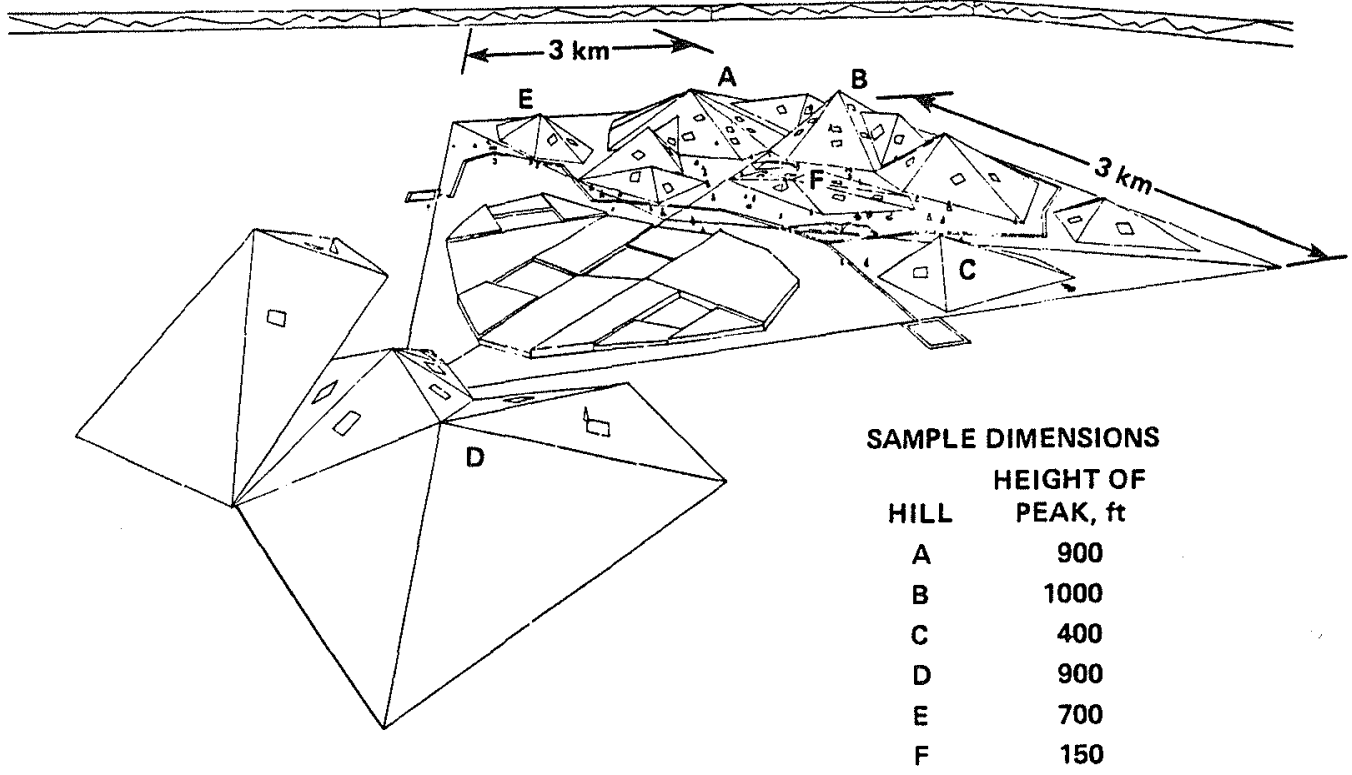

Eig. 2 CGI gaming area. 


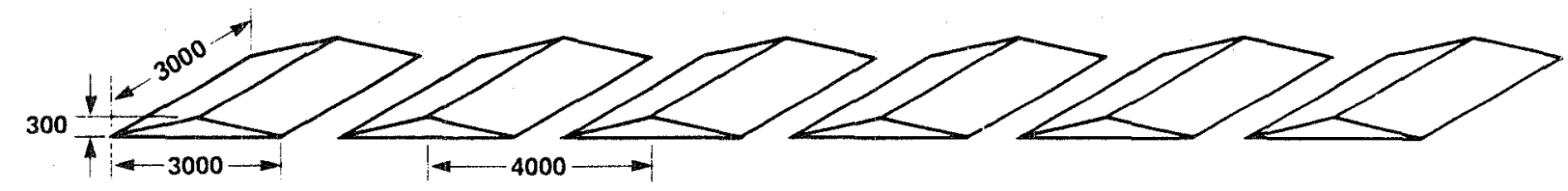

HILL SET $=2$

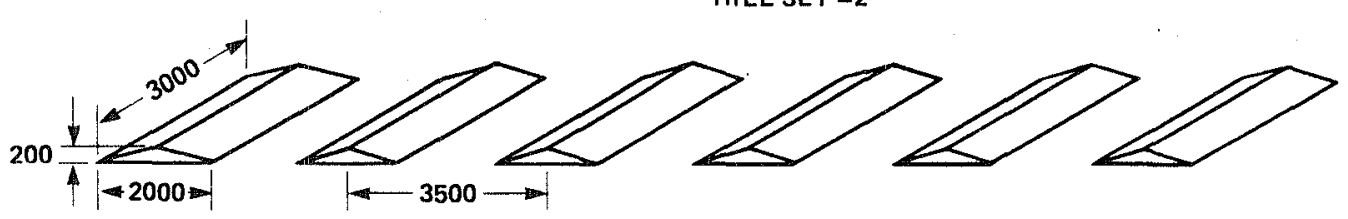

HILL SET $=3$

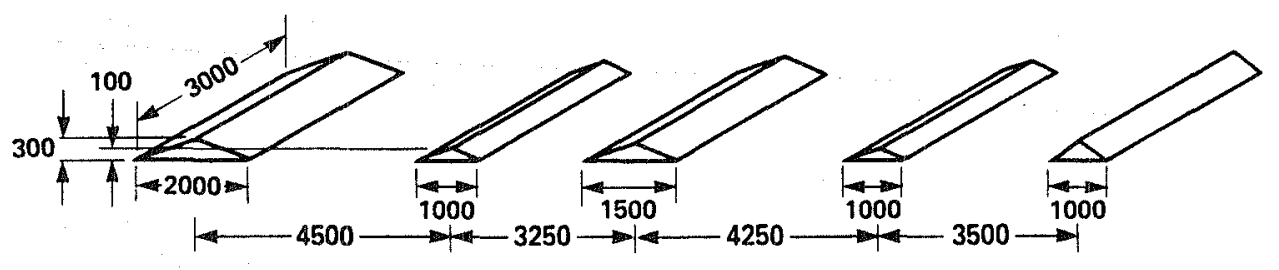

HILL SET $\# 4$

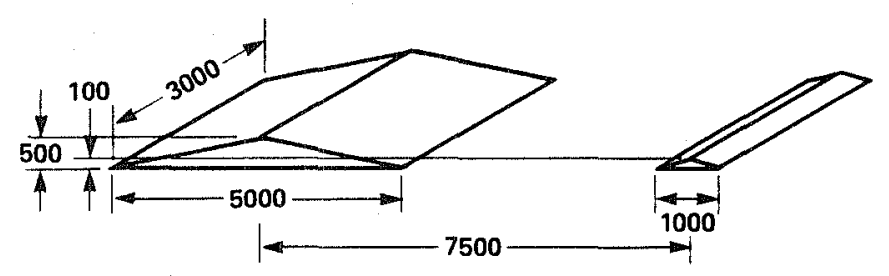

ALL DIMENSIONS IN FEET

HILL SET $=5$

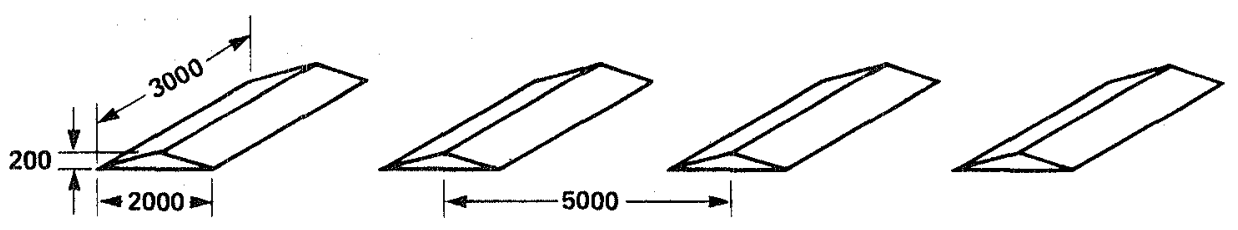

Eig. 3 CGI mountain sets.

Set ( 1 ) contained six 300-ft-high peaks with 3,000-ft-wide bases and 4,000-ft separation between peaks. Set (2) contained six 200-ft-high peaks with 2,000-ft-wide bases and 3,500-ft separation between peaks. Set (3) contained three 300-ft-high peaks with bases of 2,000, 1,500, and $1,000 \mathrm{ft}$, respectively, and two 100-ft-high peaks with 1,000-ft-wide bases; the smaller peaks were placed between the 300-ft peaks. The distance between peaks in set (3) varied, being 4,500 ft, $3,250 \mathrm{ft}, 4,250 \mathrm{ft}$, and $3,500 \mathrm{ft}$. Set (4) consisted of a 500-ft-high peak with a 5,000-ft-wide base, and a 100-ft-high peak with a 1,000-ft base; the distance between peaks was $7,500 \mathrm{ft}$. And set (5) consisted of four 200-ft-high peaks with 1,000-ft-wide bases and 5,000-ft separation between peaks. These hill sets were chosen for the purpose of giving the pilots a large dynamic range in which to perform the TF task.

Cockpit Configuration. Figure 4 shows the cockpit visual scene with the FLIR display in the pilot's center console. The cockpit was configured with conventional cyclic, collective, and pedal controls. The instrument panel includes the FLIR display, an attitude director indicator, airspeed indicator, barometric altimeter, radar altimeter, instantaneous vertical-speed indicator, dual tachometer, torque meter, and a horizontal situation indicator. 


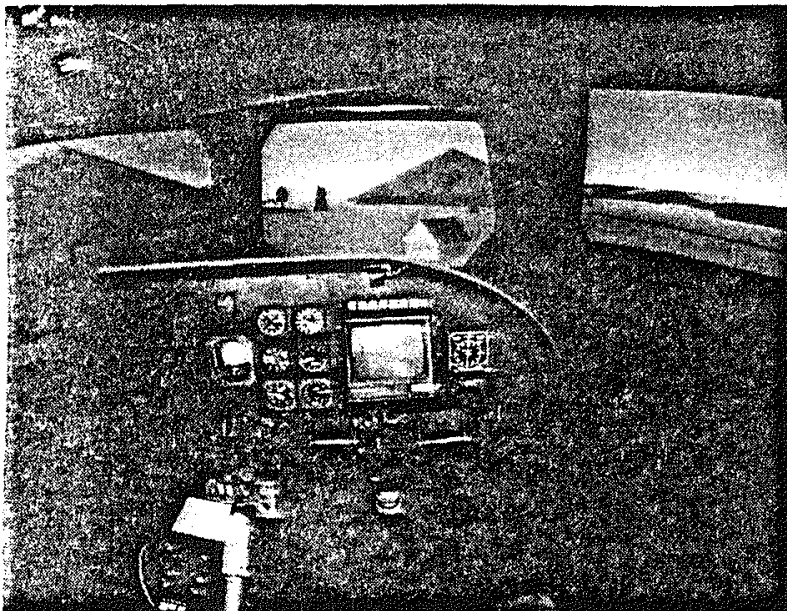

Fig. 4 Cockpit visual scene.

\section{Helicopter Simulation Model}

The helicopter that was simulated was a representation of a $\mathrm{JH}-60.4$ The mathematical model of the UH-60 is a nonlinear ten-degree-of-freedom representation of the aircraft. The degrees of freedom were six rigid body, three rotor-flapping, and the rotor rotational. Also, an attitudecommand control system was used as part of the helicopter simulation.

A model of a ground-mapping radar system was developed for this simulation. This model computed, in real time, range as a function of the forward-looking angle to the local terrain. The range was used within the terrain-following guidance algorithm. This model also computed an accurate representation of the radar altimeter over the CGI data base.

\section{FLIR Display Configurations}

The HDD used to present the simulated FLIR had a 9-in. diagonal screen. The FLIR field of view associated with this instrument was $15^{\circ} \times 20^{\circ}$. This FOV representation gave the pilot a unity magnification factor with the outside world. The center of the FLIR video was driven by the flight-path vector (EPV) angles of the aircraft to simulate a FLIR that is servoed to align with the FPV. This is done to maintain visual contact with the projected impact point. The importance of having the FLIR servoed to the FPV becomes apparent when the FPV deviates dramatically from the fuselage forward-looking body axis.

The display symbols common to all the displays are shown in Fig. 5. Airspeed, ground speed, altitude (radar and barometric), and percent power are displayed digitally. The analog information included heading tape, bank indicator, a tape on the left of the display for percent power used, and a dual scale on the right of the display for vertical velocity and radar altitude. On the bottom of the display is a course deviation indicator and a turn-and-slip indicator. The lateral and vertical command or flight director symbol was in the form of a phantom aircraft that moved about the center of the display. The airspeed cue was a bar driven by a mix of airspeed error and longitudinal acceleration. This bar was attached to the center-fixed display symbol and increased or decreased depending on the pilot's airspeed control.

The three display symbol schemes that were evaluated are shown in Figs. 6-8. The primary difference in the displays is the presentation of pitch attitude information.

In display 1 (Eig. 6a), the pitch attitude is conformal to the FLIR video. The physical center of the display is the flight-path vector for both the FLIR video and display symbols. The horizon line for display 1 is the reference for both the flight-path vector symbol and the aircraft nose symbol, thus giving the capability of reading both pitch attitude and flight-path angle (FPA). This is shown in Fig. 6a where the FPA is at $-3.5^{\circ}$ and the pitch attitude is $1.5^{\circ}$. This display gives the pilot the advantage of looking at the FLIR imagery with the conformal symbol setup and determining exactly how many degrees of vertical flight-path angle he would require to climb over a hill. It also has the potential disadvantage of losing pitch-attitude information when the FPV and pitch attitude are not within $5^{\circ}$ of one another. This is shown in Fig. 6b where the FPV is again $-3.5^{\circ}$ but the pitch attitude of the aircraft is $4.5^{\circ}$. During nominal helicopter flight this disadvantage was thought to be minimal.

The second display (Fig. 7) was an attempt to get around the potential disadvantage of display 1. As in the first display, the FPV and pitch attitude were referenced to the horizon line, but there was a threefold increase in the number of pitch-attitude reference lines. The presentation of FPV remains conformal, but pitch attitude does not. This decreases the problem of losing the pitch reference, as can be seen in Figs. $7 \mathrm{a}$ and $7 \mathrm{~b}$, but does not eliminate the problem entirely. An additional concern was the increased sensitivity in pitch attitude caused by the scaling change.

In display 3 (Figs. $8 a$ and $8 b$ ), the pitchattitude reference was located in the center of the HDD. The FLIR imagery was driven by the FPV, as it was in displays 1 and 2 . But in this display there was no reference to the FPV with the display symbols. In essence, a separation was made between the ELIR imagery and the display symbols. This display had the advantage of always displaying pitch attitude throughout the flight envelope; its disadvantage was that the symbols and imagery were no longer conformal. The pitch scaling for this display was the same as that for display 2 .

\section{Flight-Director Guidance}

Flight-director guidance was provided, on the HDD for 1) terrain following, 2) horizontal course 


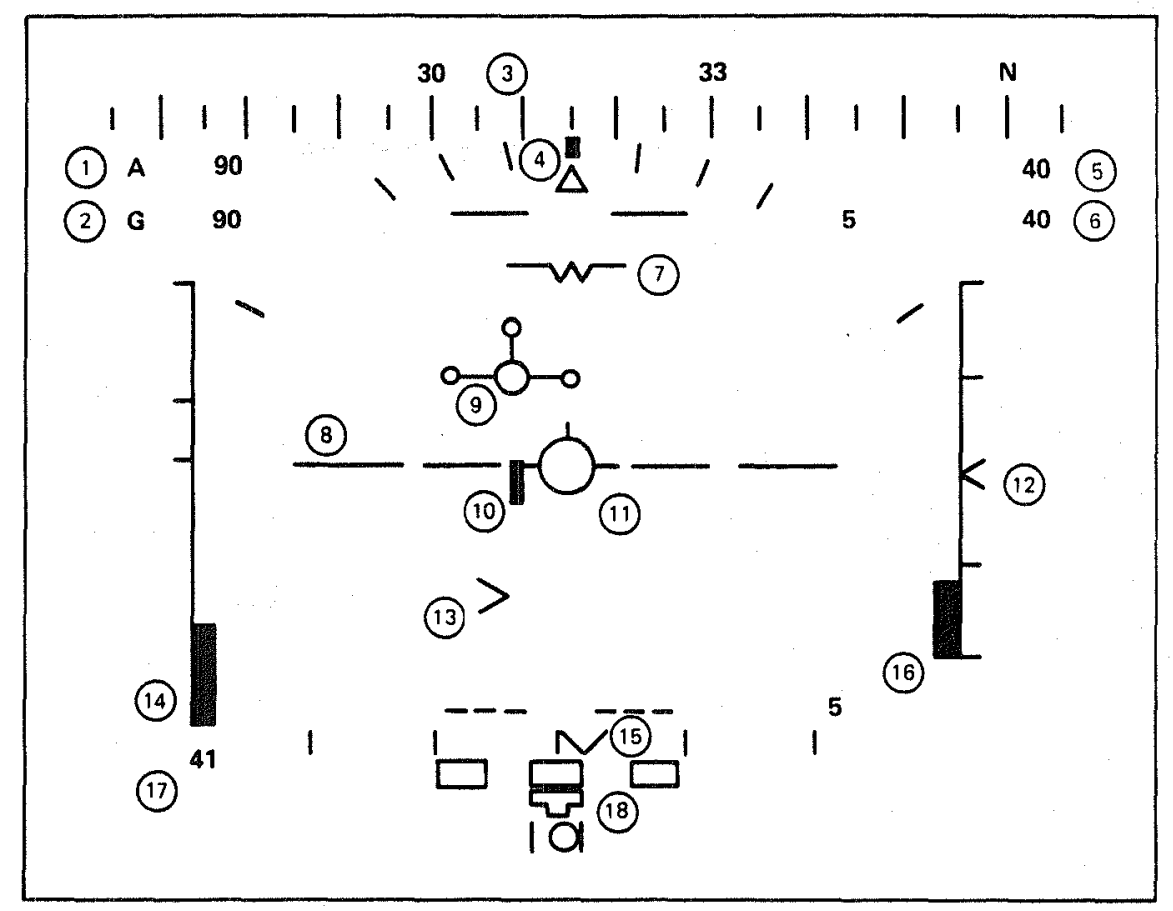

\begin{tabular}{|c|c|c|}
\hline & SYMBOL & INFORMATION \\
\hline (1) & DIGITAL AIRSPEED & AIRSPEED \\
\hline (2) & DIGITAL GROUNDSPEED & GROUNDSPEED \\
\hline (3) & HEADING & MOVING TAPE INDICATOR OF HEADING \\
\hline (4) & ROLLATTITUDE & SCALE, INDEX \& MOVING DIAMOND \\
\hline 5 & DIGITAL BARO ALTITUDE & BAROMETRIC ALTITUDE \\
\hline 6 & DIGITAL RADAR ALTITUDE & RADAR ALTITUDE \\
\hline (7) & PITCH ATTITUDE & SYMBOL REFERENCED TO HORIZON LINE \\
\hline (8) & HORIZON LINE & $\begin{array}{l}\text { SYMBOL REFERENCED TO FLIGHT PATH } \\
\text { VECTOR (FPV) SYMBOL IN DISPLAY CENTER }\end{array}$ \\
\hline (9) & PHANTOM A/C & $\begin{array}{l}\text { PROVIDES LATERAL \& VERTICAL FLIGHT } \\
\text { DIRECTOR INFORMATION }\end{array}$ \\
\hline (10) & AIRSPEED CUE & LONGITUDINAL FLIGHT DIRECTOR \\
\hline (11) & FPV SYMBOL & $\begin{array}{l}\text { FOR DISPLAY } 1 \& 2 \text { IS FPV REFERENCE } \\
\text { FOR DISPLAY } 3 \text { IS PITCH REFERENCE } \\
\text { NONMOVING SYMBOL }\end{array}$ \\
\hline (12) & VERTICAL SPEED & SCALE \& MOVING $<$ \\
\hline (13) & ACCELERATION CUE & $\begin{array}{l}\text { PROVIDES LONGITUDINAL ACCELERATION } \\
\text { INFORMATION }\end{array}$ \\
\hline (14) & POWER INDICATOR & MOVING TAPE PROVIDES PERCENT POWER. \\
\hline (15) & COURCE DEVIATION & SCALE, \& MOVING V \\
\hline (16) & RADAR ALTITUDE & RADAR ALTITUDE TAPE \\
\hline (17) & DIGITAL POWER INDICATOR & PERCENT POWER \\
\hline (18) & TURN \& SLIP & TURN \& SLIP \\
\hline
\end{tabular}

Fig. 5 Display symbols for HDD.

steering, 3) airspeed hold, and 4) approach to hover. The TF law was based on the advanced lowaltitude technique (ADLAT) originally developed by Cornell Aeronautical Laboratory ${ }^{5}$ (now Arvin/ Calspan). The TF guidance moved the phantom aircraft symbol vertically, which provided a "fly-to" collective command. The TF commands gave the pilot precisde vertical flight-path control, which made possible crossings at $100 \mathrm{ft}$ above ground level (AGL), and zero flight-path angle at the mountain peaks. The horizontal course-steering, airspeed-hold, and approach-to-hover guidance 


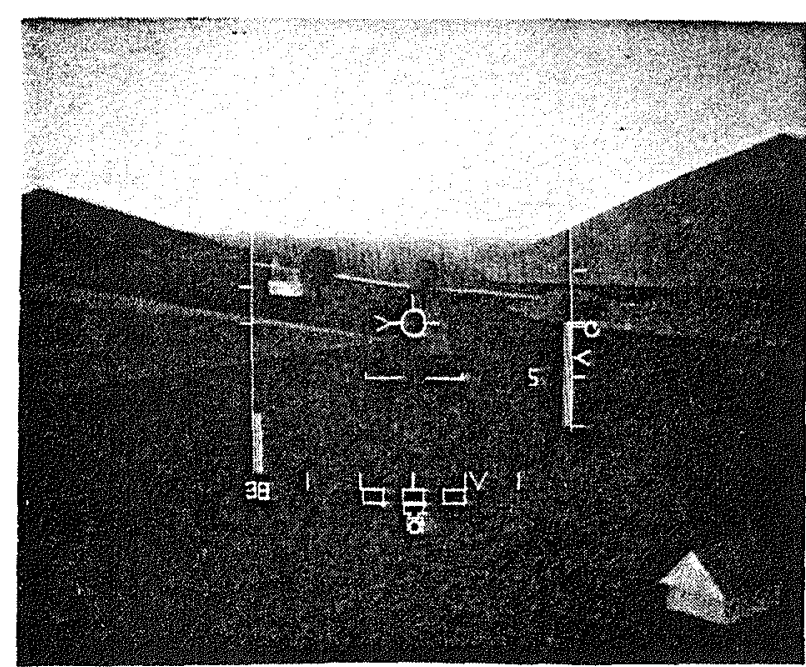

a)

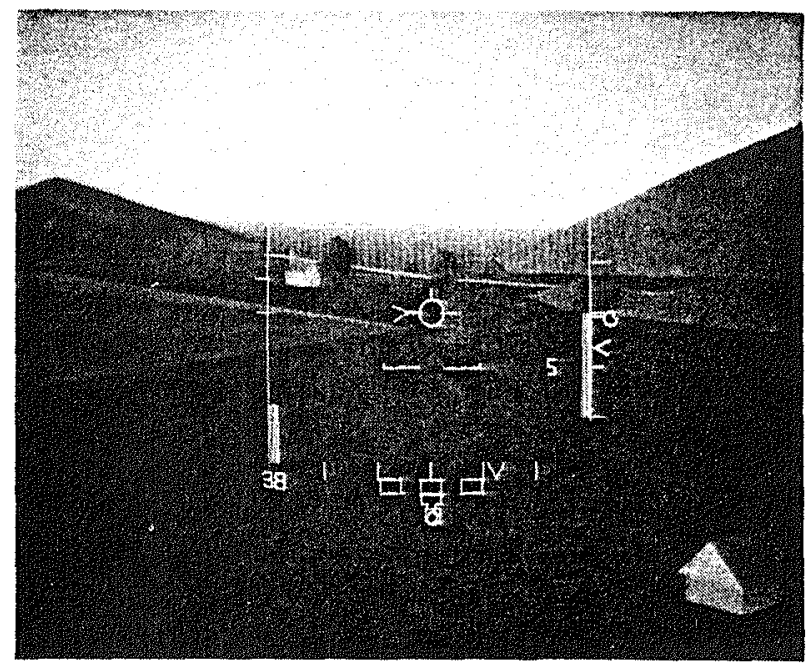

b)

Fig. 6 Head-down display No. 1: flight-path angle $=-3.5^{\circ}$. a) Pitch attitude $=1.5^{\circ} ;$ b) pitch attitude $=4.5^{\circ}$.

modes were similar to those of the $\mathrm{HH}-60.5,6$ The course-steering command was displayed by lateral movement of the phantom aircraft symbol, again in a "fly-to" sense. The airspeed-hold cue increased or decreased from the center of the display to command longitudinal cyclic control. The approach-to-hover mode was identical to the course-steering mode in the lateral direction but also provided a controlled deceleration to a hover point as a function of range-to-go (RTG) to that point. The velocity-profile portion of the approach-to-hover guidance gave a constant deceleration profile, with a decaying exponential flare at the end. The pilot was signaled that he would be following this deceleration profile by the presence of a flashing " $G$ " to the right and above the center on his display; the "G" flashed for $5 \mathrm{sec}$.

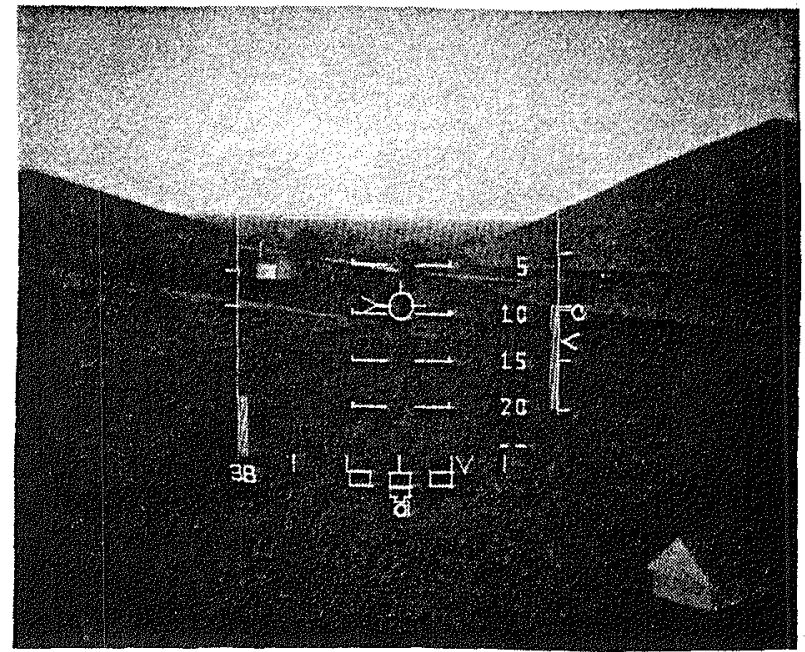

a)

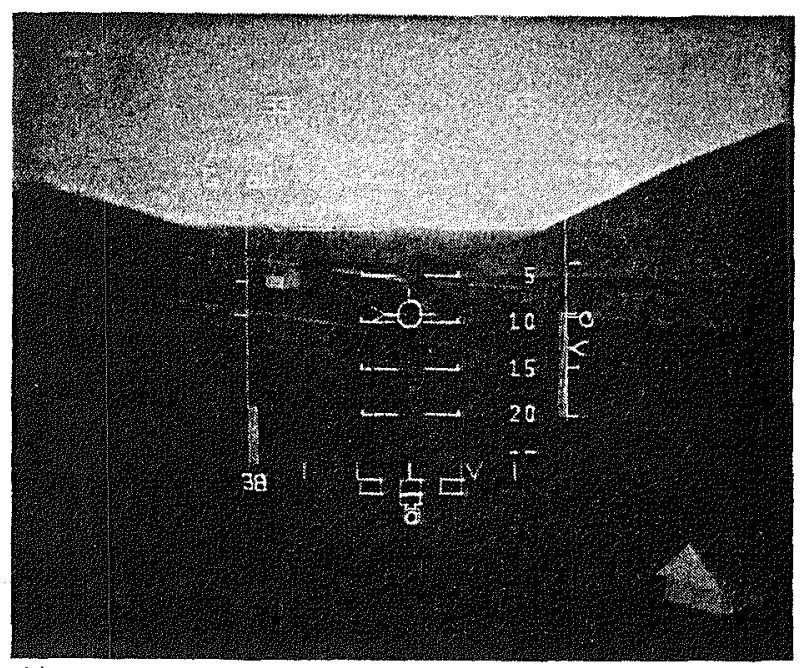

b)

Fig. 7 Head-down display No. 2: flight-path angle $=-3.5^{\circ}$. a) Pitch attitude $=1.5^{\circ} ;$ b) pitch attitude $=4.5^{\circ}$.

\section{Test Description}

\section{Pilot Tasks Evaluated}

Three tasks were the basis for the pilot evaluations during the simulation. The first task was TF at $100 \mathrm{ft}$ ACL at a constant speed of 60 knots along a prescribed course. The second task was also $\mathrm{TF}$ at $100 \mathrm{ft}$ along a prescribed course but at a speed of 90 knots. The third was a deceleration to a hover while $T F$ along a prescribed course. All these tasks were performed with positive guidance, that is, the pilot used flight-director information to assist in doing the task.

These three tasks were performed over each of the five hill sets described earlier. The tasks 


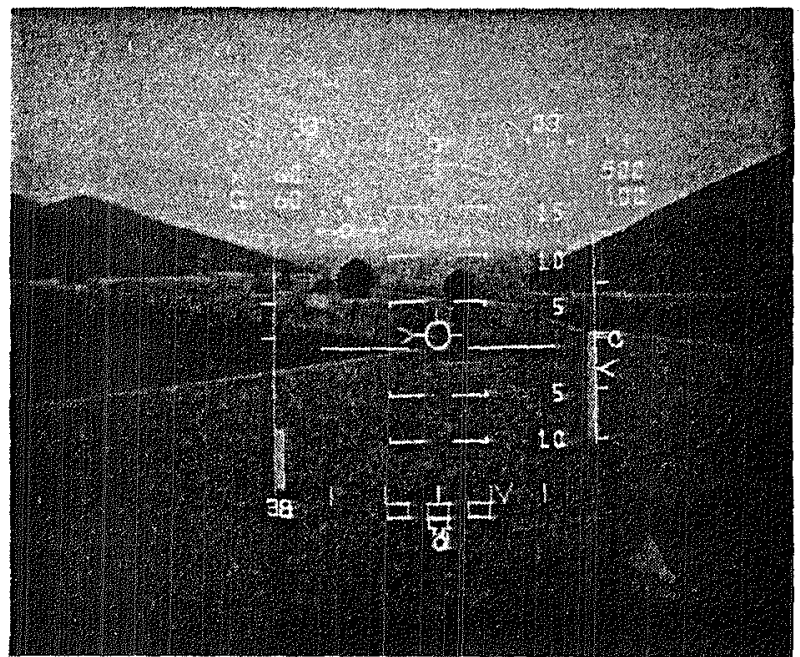

a)

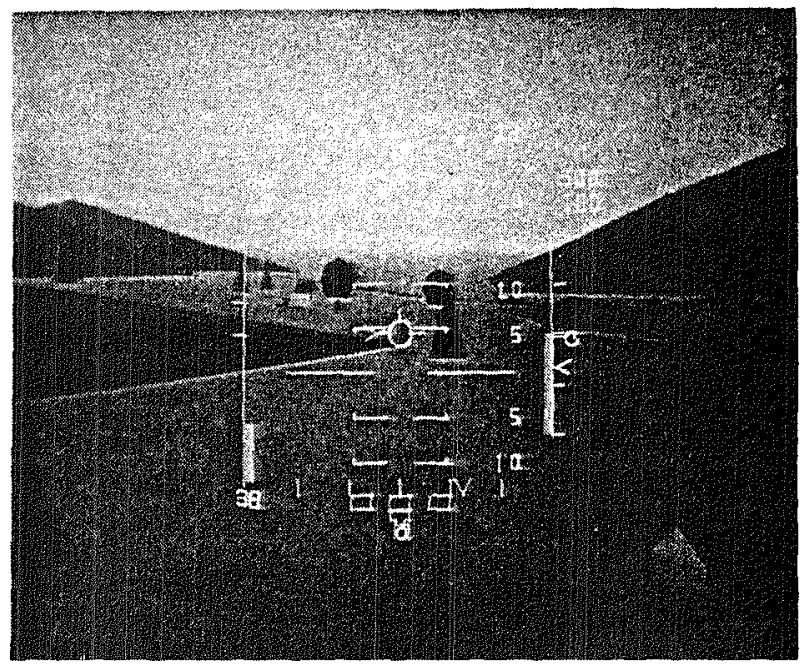

b)

Eig. 8 Head-down display No. 3: flight-path angle $=-3.5^{\circ}$ a) Pitch attitude $=1.5^{\circ}$; b) pitch attitude $=4.5^{\circ}$.

were also flown during a night simulation, which was done by turning of $f$ the three-window visual CGI displays and leaving only the FLIR display on for the pilot's use. The tasks were also performed in the presence of moderate turbulence.

\section{Pilot Procedures}

The pilot procedures for each of the tasks were as follows. The pilot started each run with a lateral offset of $1 \mathrm{n}$. $\mathrm{mi}$. and parallel to the preselected course with initial airspeeds of 60 or 90 knots. The pilot would engage the following flight-director modes: TF, airspeed-hold, and course-steering or approach to hover. Once the pilot had initiated the appropriate director modes, he followed the flight-director guidance.

\section{Test Scope}

Four test pilots participated in the evaluations: two USAF pilots presently assigned to test the HH-60 helicopter at Edwards AFB, and two NASA research pilots. The first pilot had over $3,000 \mathrm{hr}$ of helicopter time, $100 \mathrm{hr}$ in the $\mathrm{HH}-60$, and over $1,000 \mathrm{hr}$ of helicopter $\mathrm{TE}$ experience in the H-53 Pave Low III aircraft. The second pilot had over 2,000 hr of helicopter time, $50 \mathrm{hr}$ in the $\mathrm{HH}-60$, and $T E$ experience with the $\mathrm{UH}-1 \mathrm{~N}$ special operations. The third pilot had over $1,200 \mathrm{hr}$ of hellcopter time along with experience in the AH-64 pilot night-vision system. The fourth pilot had over $7,000 \mathrm{hr}$ of flight time with $150 \mathrm{hr}$ of helicopter time and over $20 \mathrm{yr}$ of experience in evaluating advanced cockpit display configurations. Most of the data runs were conducted by the first two pilots.

During the simulation, 207 data collection runs were made. Most of the runs were conducted on hill-sets 2 through 5 (Fig. 3). A11 three of the pilot tasks were accomplished on each of the hill sets during daytime conditions. Additionally, hill-set 3 was used to collect data on displays 1 and 3 in nighttime conditions, and with moderate turbulence during daytime conditions.

\section{Test Method}

The pilots were asked to give Cooper-Harper ratings ${ }^{8}$ after each run for the TF task at the different airspeeds, the course-steering task, and the approach-to-hover task. The different displays and hill sets were given as the independent variable. Real-time flight-data variables were collected during each approach.

\section{Results and Discussion}

\section{Pilot Evaluations}

The Cooper-Harper pilot ratings for the three pilot tasks using the three displays are shown in $\mathrm{Fig.} \mathrm{9.} \mathrm{The} \mathrm{mean} \mathrm{rating} \mathrm{is} \mathrm{indicated} \mathrm{by} \mathrm{the}$ symbol, and the standard deviations are given by the bar. The standard deviations are based on 13 to 15 data points each. It can be seen that all three displays were rated acceptable, with slightly better ratings in all three cases for display 3. Although the ratings were similar for the three displays, the pilots made several comments regarding the inadequacy of displays 1 and 2 for attitude awareness or for making precise pitch-attitude changes to the aircraft. These concerns were not reflected in the ratings, however, because the task did not require continued attitude awareness or precise pitch-attitude information. It is believed that there would be greater differences between the ratings assigned to the three displays if, in a more representative evaluation, the pilot was not following guidance in all axes or if he encountered a failure of the flight-director guidance that would require precise attitude changes. 


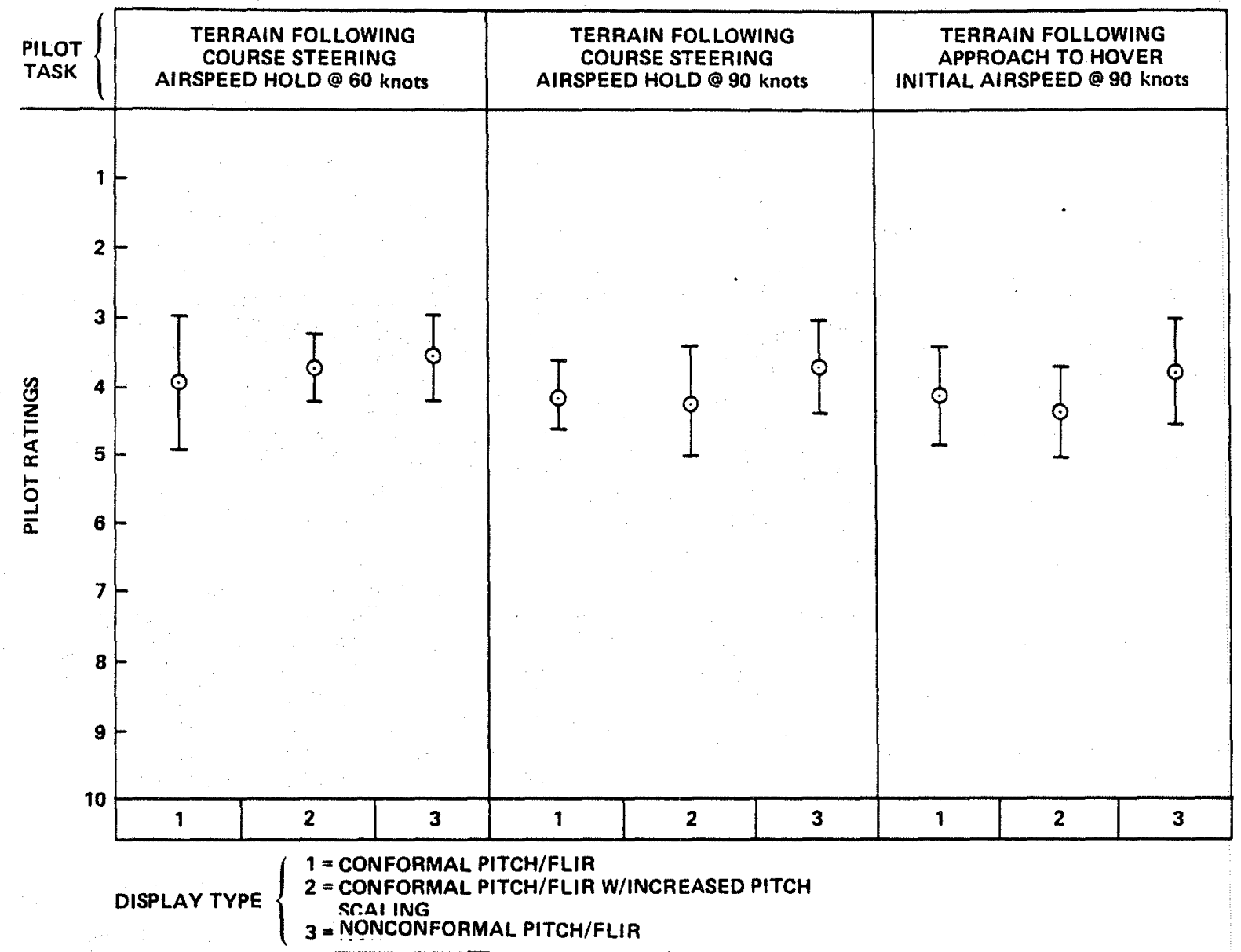

Fig. 9 Pilot ratings by task and display.

The major reason that the pilot could not make precise attitude changes with either display 1 or 2 was that during active TF, the pitch attitude and the FPV deviate dramatically from one another. Figure 10, which is representative of

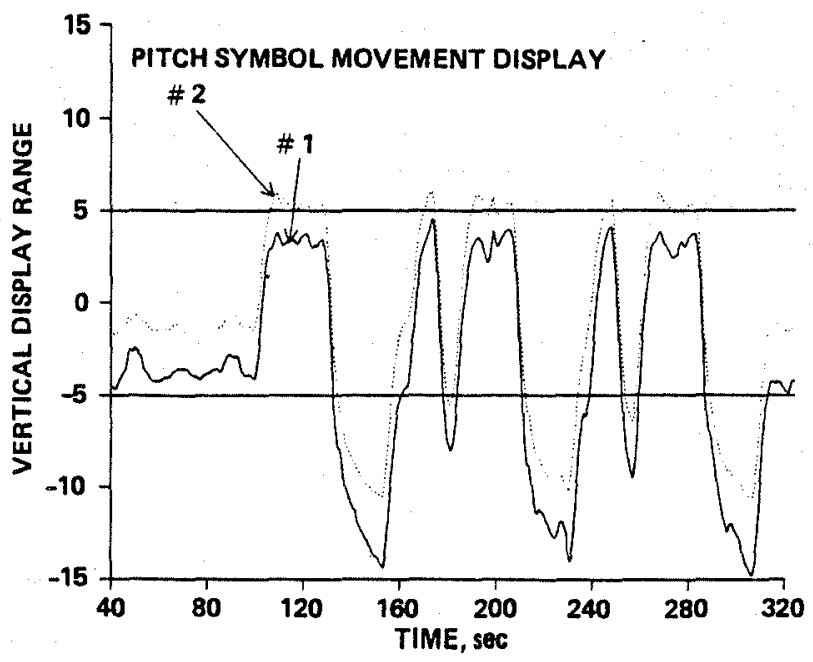

Fig. 10 Pitch-attitude symbol movement: manual $\mathrm{TF}, 60$ knots, hill-set 3 . all the runs over hill-set 3 , is an attempt to show this problem graphically. Shown are timehistories of the movement of the pitch-attitude symbol on displays 1 and 2 . The solid lines at \pm 5 represent the full-scale deviations of the display. The solid line represents the movement of the pitch-attitude symbol for display 1 and the dotted for display 2. What this plot shows is that during TF, when the FPV is moving rapidly, the pilot loses the pitch-attitude symbol from his display. The figure shows that even with the increase by three in pitch scaling, the problem of attitude-information loss is not reduced and may even be greater. In display 3, where the pitch attitude was not reference to the FPV, the pilot never has this problem. The pilots felt that display 3 was the only one of the three that allowed attitude awareness and made it possible for them to make precise attitude changes. It is interesting to note (Fig. 9) that there is a much greater difference in the ratings between displays for the approach-to-hover task. Possibly this reflects the pilot's used pitch attitude as a major control for deceleration, and display 3 is the only one that lets him precisely monitor that control. In addition to the three principal tasks evaluated in this study, pilot ratings were 
abtained for runs at night and in turbulence. The ratings assigned to the three displays are not shown here, but they were similar to those shown in Fig. 9. It was mentioned earlier that the different hill sets were chosen to increase the difficulty of the TF task. The pilots felt that none of the hill sets showed any great disparity in difflculty.

\section{Performance Results}

As mentioned earlier, the pilots were able to maintain reasonably precise flight-path control using any of the displays. Terrain-following performance plots for all the displays are shown in Figs. 11-13. The plots are composites of the constant-speed ( 60 and 90 knots), TF and coursesteering tasks over hill-set 3 , with hill-set 3 superimposed on the plot. The plots show the vertical tracking performance of the pilots over the hills. The plots are read from right to left with zero being the end of the run.

These plots show good TF performance, with peak crossings at the preselected 100-ft ( $\pm 10 \mathrm{ft}$ ) AGL and with very little ballooning on the backside of the hills. There were no significant differences in performance between the display formats, which confirms the pilots' comments that all three displays were adequate for flightpath control. The authors looked at many other
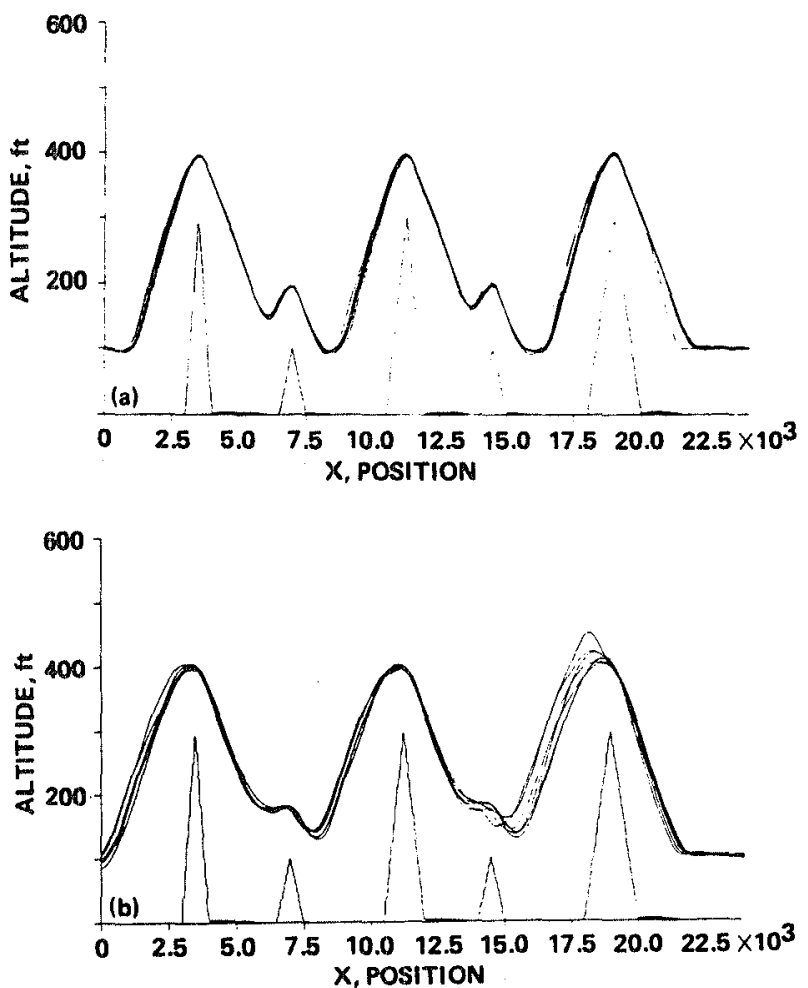

Fig. 11 Terrain-following performance plots, hill-set 3: display No. 1, manual TF.

a) 60 knots; b) 90 knots.

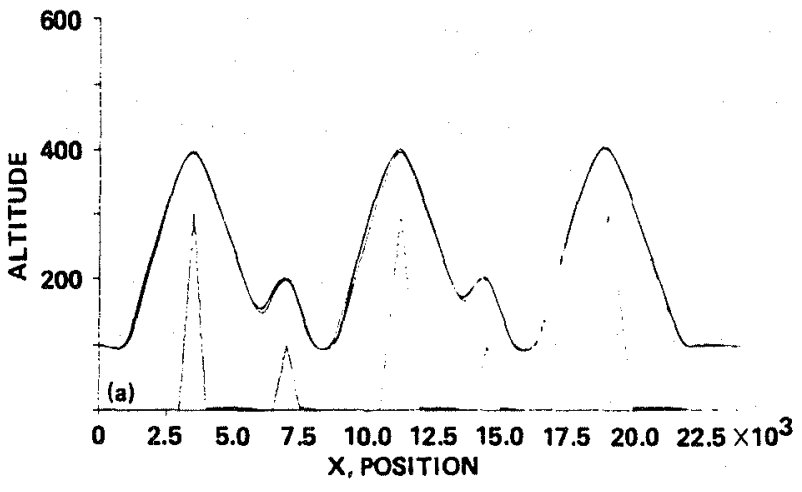

600

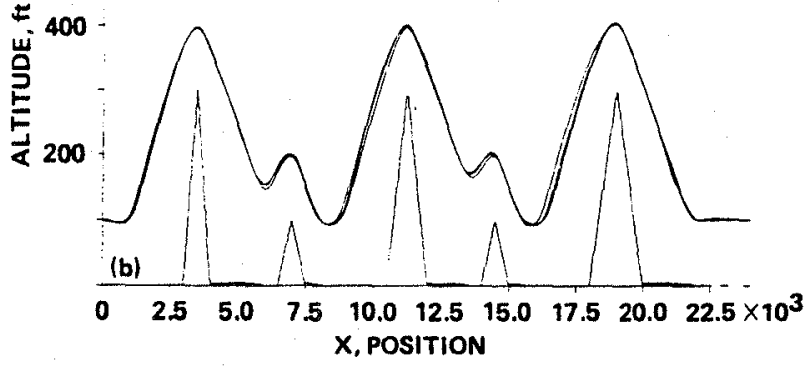

Fig. 12 Terrain-following performance plot, hillset 3: display No. 2, manual TF. a) 60 knots; b) 90 knots.

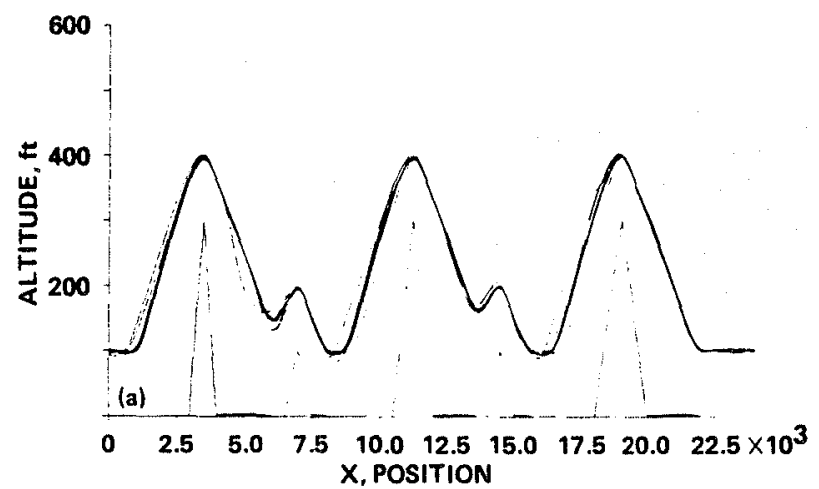

600

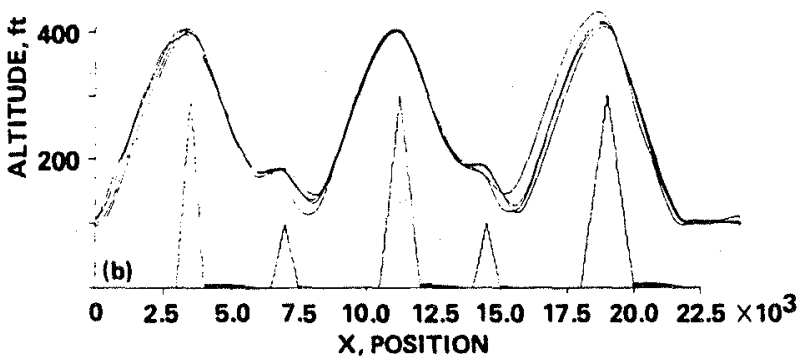

Fig. 13 Terrain-following performance plots, hill-set 3: display No. 3 , manual $T F$.

a) 60 knots; b) 90 knots. 
flight variables such as airspeed control, stick positions, attitude changes, and flight-director deviations and found similar results as described here, that is, insignificant differences between the three displays.

\section{Conclusions}

The following conclusions were drawn from the pilot ratings, pilot comments, and simulation performance data.

1) All three pilot displays and display symbols proved adequate for the pilot tasks performed.

2) The investigation of how to integrate a limited-field-of-view FLIR with display symbols led to a nonconformal FLIR-display superposition being preferred by the pilots.

3) The guidance laws from the HH-60 enabled satisfactory pilot performance for all tasks.

\section{Acknowledgments}

The authors are grateful to Bryan Martin and Martin Barrera (Ames Research Center) for their invaluable assistance in the data analysis, and to Gordon Hardy and Lt. Col. Pat Morris (Ames Research Center) and Major Stephen Connelly and Major Stetson Cowan (Edwards AFB) for their participation as evaluation pilots.

\section{References}

${ }^{1}$ Clifford, James, E., "PAVE Low III, A LongAwaited Capability: Lessons Learned and Projections," NAECON Conference Proceedings, 1979.

${ }^{2}$ Jones, A. D., "Operations Manual: Vertical Motion Simulator (VMS) S.08," NASA TM-81180, 1980.

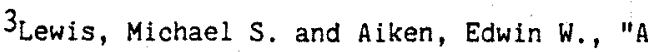
Plloted Simulation of One-on-One Helicopter Air Combat at NOE Flight Levels," NASA TM-86686, 1985.

${ }^{4}$ Hilbert, Kathryn B., "A Mathematical Model of the UH-60 Helicopter," NASA TM-85890, 1984.

${ }^{5}$ Kilmer, F. G., Kilmer, R. L., and Thalacker, B. A., "Digital Avionios and Flight Path Director Functions of the HH-60 Helicopter," AIAA Paper 84-2674-CP, 1984.

${ }^{6}$ Mills, C. A., Kilmer, F. G., and Kilmer, R. L., "Description and Analysis of the HH-60D Guidance and Director Functions," IBM Report No. 673-2152, Owego, N.Y., Mar. 6, 1984.

${ }^{7}$ Schwartz, E. C., "ADLAT Terrain Avoidance Techniques Evaluation," Cornell Aeronautical Laboratory Report No. AL TDR-64-145, Ithaca, N.Y., Aug. 1964.

${ }^{8}$ Cooper, G. E. and Harper, R. P., "The Use of Pilot Rating in the Evaluation of Aircraft Handling Qualities," NASA TN D-5153, 1969. 


\begin{tabular}{|c|c|c|c|}
\hline $\begin{array}{l}\text { 1. Report No. } \\
\text { NASA TM86779 }\end{array}$ & 2. Government Accession No. & \multicolumn{2}{|c|}{ 3. Recipient's Catalog No. } \\
\hline \multirow{2}{*}{\multicolumn{2}{|c|}{$\begin{array}{l}\text { 4. Title and Subtiti } \\
\text { Simulation Evaluation of Display/Fifr. Concepts } \\
\text { for Low-Altitude, Terrain-Following Helicopter } \\
\text { Operations }\end{array}$}} & \multicolumn{2}{|c|}{$\begin{array}{l}\text { 5. Report Date } \\
\text { December } 1985\end{array}$} \\
\hline & & \multicolumn{2}{|c|}{ 6. Performing Organization Code } \\
\hline \multirow{2}{*}{\multicolumn{2}{|c|}{$\begin{array}{l}\text { 7. Author(s) } \\
\text { Harry N. Swenson, Clyde H. Paulk, Jr., Robert L. } \\
\text { Kilmer* and Frank G. Kilmer* }\end{array}$}} & \multicolumn{2}{|c|}{$\begin{array}{l}\text { 8. Performing Organization Report No. } \\
85349\end{array}$} \\
\hline & & \multirow{2}{*}{\multicolumn{2}{|c|}{ 10. Work Unit No. }} \\
\hline \multirow{2}{*}{\multicolumn{2}{|c|}{$\begin{array}{l}\text { 9. Performing Organization Name and Address } \\
\text { Ames Research Center, Moffett Field, CA } 94035 \\
\text { *IBM, Federal Systems Division, Owego, NY }\end{array}$}} & & \\
\hline & & \multicolumn{2}{|c|}{ 11. Contract or Grant No. } \\
\hline & & \multirow{2}{*}{\multicolumn{2}{|c|}{$\begin{array}{l}\text { 13. Type of Report and Period Covered } \\
\text { Technical Memorandum }\end{array}$}} \\
\hline \multirow{2}{*}{\multicolumn{2}{|c|}{$\begin{array}{l}\text { 12. Sponsoring Agency Name and Address } \\
\text { National Aeronautics and Space Administration } \\
\text { Washington, DC, } 20546\end{array}$}} & & \\
\hline & & \multicolumn{2}{|c|}{$\begin{array}{l}\text { 14. Sponsoring Agency Code } \\
532-06-11\end{array}$} \\
\hline \multicolumn{4}{|c|}{$\begin{array}{l}\text { 15. Supplementary Notes } \\
\text { Point of contact: }\end{array}$} \\
\hline \multicolumn{4}{|c|}{$\begin{array}{l}\text { 16. Abstract } \\
\text { A piloted simulation of three head-down display (HDD) concepts with } \\
\text { flight-director guidance superimposed on forward-looking infrared (FLIR) } \\
\text { imagery was performed to evaluate the task of low-level, terrain-following } \\
\text { (TF), manual helicopter flight. The three display concepts were examined } \\
\text { for the purpose of finding ways by which aircraft flight-attitude and } \\
\text { command symbols and FLIR imagery could be integrated onto one instrument. } \\
\text { In all cases, the FLIR imagery was centered on the flight-path vector } \\
\text { of the aircraft. The three displays were then characterized by having } \\
\text { (1) pitch attitude conformal to the FLIR imagery; (2) pitch, but with } \\
\text { an increase in the scaling; and (3) pitch attitude nonconformal to the } \\
\text { FLIR imagery with the same pitch scaling as in (2). The simulation was } \\
\text { conducted on the vertical motion simulator (VMS) at Ames Research Center, } \\
\text { using NASA and Air Force test pilots. The pilots performed the TF task } \\
\text { (over various types of terrain characteristics) by following flight- } \\
\text { director symbols derived from terrain-following and course-steering } \\
\text { guidance developed for the HH-60D helicopter. The pilots indicated } \\
\text { that the nonconformal pitch attitude and FLIR display was the preferred } \\
\text { way to display information because of the absence of pitch-attitude } \\
\text { information on displays (1) and (2) during some portions of the } \\
\text { operational flight envelope and because of the difficulty in interpreting } \\
\text { pitch attitude with displays (1) and (2) even when available. }\end{array}$} \\
\hline \multicolumn{4}{|c|}{$\begin{array}{l}\text { 17. Key Words (Suggested by Author(s)) } \\
\text { Helicopters } \\
\text { Pilot displays } \\
\text { FLIR imagery } \\
\text { Terrain following }\end{array}$} \\
\hline $\begin{array}{l}\text { 19. Security Classif. (of this report) } \\
\text { Uncl }\end{array}$ & $\begin{array}{l}\text { 20. Security Classif. (of this page) } \\
\text { Unc1 }\end{array}$ & $\begin{array}{l}\text { 21. No. of Pages } \\
12\end{array}$ & $\begin{array}{l}\text { 22. Price } \\
\mathrm{A} 02\end{array}$ \\
\hline
\end{tabular}

"For sale by the National Technical Information Service, Springfield, Virginia 22161 
End of Document 